J. Dairy Sci. 96:3517-3524

http://dx.doi.org/10.3168/jds.2012-6466

(C) American Dairy Science Association ${ }^{\circledR}, 2013$.

\title{
Long-term detection of Mycobacterium avium subspecies paratuberculosis in individual and bulk tank milk from a dairy herd with a low prevalence of Johne's disease
}

\author{
J. L. Khol,* M. Wassertheurer, ${ }^{*}$ E. Sodoma,† S. Revilla-Fernández,† J. Damoser,§ E. Österreicher,§ \\ M. Dünser,† U. Kleb,\# and W. Baumgartner* \\ ${ }^{*}$ Clinic for Ruminants, Department for Farm Animals and Veterinary Public Health, University of Veterinary Medicine, Vienna 1210, Austria \\ †Institute for Veterinary Disease Control Linz, Agency for Health and Food Safety, Linz 4020, Austria \\ fInstitute for Veterinary Disease Control Mödling, Agency for Health and Food Safety, Mödling 2340, Austria \\ $\S$ Austrian Federal Ministry of Health, Vienna1030, Austria \\ \#Joanneum Research, Centre for Economic and Innovation Research, Statistical Applications, Graz 8010, Austria
}

\section{ABSTRACT}

Mycobacterium avium ssp. paratuberculosis (MAP) causes Johne's disease (JD) in ruminants and is shed into the milk of infected cows, which contributes to the controversial discussion about a possible link between MAP and Crohn's disease in humans. The aim of the study was to investigate the risk for the entry of MAP in the food chain via milk from dairy farms with subclinical JD. Therefore, the occurrence of MAP in the milk of a dairy herd with a low prevalence of JD was studied in single and bulk tank milk samples over a period of 23 mo and compared with MAP shedding into feces. Milk, fecal, and blood samples were taken from all cows older than $1.5 \mathrm{yr}$ of age at the beginning and the end of the trial and analyzed for MAP or specific antibodies. In addition, 63 cows (33 MAP infected and 30 MAP noninfected) were selected for monthly sampling. Raw and pasteurized bulk tank milk samples were collected on a monthly basis. The milk samples were tested for MAP by real-time quantitative PCR ( $\mathrm{qPCR}$ ), and the fecal samples were tested for bacterial shedding by qPCR or solid culture. Based on the results of the herd investigations, the prevalence of cows shedding MAP was around $5 \%$; no cases of clinical JD were observed during the study period. The results of the ELISA showed high variation, with 2.1 to $5.1 \%$ positive milk samples and 14.9 to $18.8 \%$ ELISA-positive blood samples. Monthly milk sampling revealed low levels of MAP shedding into the individual milk samples of both MAP-infected and noninfected cows, with only 13 cows shedding the bacterium into milk during the study period. Mycobacterium avium ssp. paratuberculosis was not detected by $\mathrm{qPCR}$ in any raw or pasteurized bulk tank milk sample throughout the study. A significant positive association

Received December 10, 2012.

Accepted March 1, 2013.

${ }^{1}$ Corresponding author: johannes.khol@vetmeduni.ac.at could be found between MAP shedding into milk and feces. From the results of the present study, it can be concluded that MAP is only shed via milk in a small proportion of cows with subclinical JD for a limited period of time and is diluted below the detection level of qPCR within the bulk tank milk of these herds. These findings indicate that dairy herds subclinically infected with JD pose only a minor source for human MAP consumption with milk and milk products.

Key words: Johne's disease, milk, Mycobacterium avium ssp. paratuberculosis, paratuberculosis

\section{INTRODUCTION}

Mycobacterium avium ssp. paratuberculosis (MAP) causes Johne's disease (JD), or paratuberculosis, in ruminants worldwide (Barkema et al., 2010). Due to severe economic losses in affected herds (Hasonova and Pavlik, 2006), JD is seen today as one of the most important infectious diseases of ruminants in developed countries and is listed by the World Organisation for Animal Health (OIE, 2010).

Infected cattle frequently shed large amounts of MAP into their feces, milk, and colostrum, thereby leading to fecal-oral transmission, which is the most important route of infection. The incubation period of JD may range from 1 to $10 \mathrm{yr}$ and the symptoms of clinical JD include cachexia and severe diarrhea, finally leading to the death of the animal (Fecteau and Whitlock, 2010).

Due to the lack of accurate laboratory tests, the diagnosis of paratuberculosis is challenging in subclinically infected cattle (Collins, 1996). Direct methods, such as fecal culture and PCR as well as indirect methods to measure humoral immune response, are used. Bacterial culture from fecal samples show a specificity of $98 \%$, but sensitivity is only 23 to $49 \%$ in subclinically infected individuals (Nielsen and Toft, 2008). Polymerase chain reaction can be used for the direct detection of MAP in milk, feces, blood, and tissue samples. The specificity 
of the PCR is reported to be close to $100 \%$, depending on the method used, but sensitivity is as low as $53 \%$ (Nielsen et al., 2001; Diéguez et al., 2009). The ELISA technique is the most commonly used laboratory test for the detection of specific antibodies against MAP in serum and milk today. The sensitivity and specificity of ELISA vary widely, depending on the product and gold standard applied. For testing milk, the sensitivity of the ELISA ranges between 21 and $61 \%$ and the specificity between 83 and $98 \%$ (Nielsen and Toft, 2008).

The percentage of infected animals shedding MAP into milk varies depending on the stage of the infection and the diagnostic method used. Up to $35.0 \%$ of the milk samples from infected cows were found to be MAP positive by bacterial culture and up to $77.8 \%$ by quantitative PCR (qPCR; Slana et al., 2008). Several studies have shown that MAP is able to survive milk pasteurization and cheese production under certain circumstances (Slana et al., 2008). The bacterium has also been detected by PCR in a high proportion of commercial dried milk baby food products (Hruska et al., 2011). These findings contribute to the controversial discussion about a possible link between MAP and Crohn's disease in humans (Feller et al., 2007; Uzoigwe et al., 2007) and lead to concerns about the possible consequences for consumers about the uptake of the bacterium with milk and milk products (Feller et al., 2007). Calculations of different scenarios estimated a possible reduction of the US consumer surplus of up to $\$ 2.9$ billion and a reduction of farm income of $\$ 1.3$ billion if a link between JD in cattle and Crohn's disease in humans would be scientifically established (Groenendaal and Zagmutt, 2008).

The first objective of this study was to evaluate the occurrence of MAP in the milk of cows from a dairy herd with a low prevalence of subclinical JD over an extended period of time. The second objective was to compare individual MAP shedding into milk to fecal shedding as well as to the detection of MAP in bulk tank milk. The overall aim of the study was to investigate the risk of MAP entering the food chain with milk from dairy cows subclinically infected with JD.

\section{MATERIALS AND METHODS}

\section{Study Herd}

The size of the study herd varied between 165 and 175 cows older than 1.5 yr (1.7 to $10.6 \mathrm{yr}$; mean age 4.4 yr). The predominant breed was Holstein (HS; 86.1\%), followed by Austrian Simmental (SIM; 11.0\%) and Brown Swiss (0.6\%) as well as $2.3 \%$ crossbred cows. Animals were fed a TMR and kept in a loose housing system with cubicles. Cows were milked twice per day in a rotary milking parlor, and the milk was mainly processed in a small dairy connected to the farm and distributed locally. The surplus milk was delivered to a commercial dairy. Calves were separated from their dams immediately after birth and housed in single hutches. Calves were fed individual colostrum for $3 \mathrm{~d}$, which was followed by the feeding of acidified milk until weaning at 13 wk of age. Heifers for replacements were raised outside the farm and returned to the farm for calving. Prior to the start of the present study, the herd had been tested for JD by the Austrian Agency for Health and Food Safety, Institute for Veterinary Disease Control Mödling, Austria. At that time, 9.0\% of the adult animals were positive for MAP in qPCR of fecal samples and the 8 animals that had clinical signs of JD were recorded and removed from the herd before the beginning of the study.

\section{Sampling Scheme}

To assess the MAP herd status, blood, milk, and fecal samples were investigated twice at the beginning and once at the end of the trial in all cows with an age of 18 mo or older. These 3 investigations were called first, second, and third herd investigation and were carried out in January 2005 (first herd investigation), April 2005 (second herd investigation), and November 2006 (third herd investigation).

From November 2005 to October 2006, monthly follow up investigations of 63 animals, selected as described hereunder, were performed. To compare the shedding of the bacterium in cows with a suspected MAP infection with cows assumed to be noninfected, 33 of the 63 cows were selected to have a high and 30 to have a low index of suspicion of being infected with MAP. Cows with a suspected MAP infection were selected based on positive test results in the first and second herd investigation. Four of these cows (12.1\%) showed positive fecal results, another $4(12.1 \%)$ were positive by qPCR in milk, and 1 cow (3.0\%) showed positive MAP results in the fecal and milk samples. Three $(9.1 \%)$ of the cows selected as MAP suspicious had positive fecal and ELISA results, whereas $4(12.1 \%)$ were positive in milk and serum ELISA, and $17(51.5 \%)$ were only positive in blood ELISA. These 33 cows were called MAP infected and matched according to age, lactation, and milk yield, with 30 cows of the herd showing negative results in all the tests performed at the initial and second herd investigation called MAP noninfected. The mean age of the MAP-infected cows was 55.6 mo (21-110 mo.), compared with a mean age of 54.3 (22-112 mo.) in noninfected cows, with a mean of 2.7 (1 to 7 ) lactations in both groups. The average daily milk yield was $22.7 \mathrm{~L}$ (minimum: 4.2; maximum: 42.2) in MAP-infected and 
28.7 L (minimum: 10.8; maximum: 48.0) in noninfected animals. Of the 33 MAP-infected cows, 97.0\% (32) belonged to the HS and $3.0 \%$ (1) to the SIM breed. The group of noninfected animals consisted of $93.3 \%$ (28) HS and $6.7 \%$ (2) SIM cows. The selected animals stayed in their production groups within the herd and no differences in management and housing were made between them and the other animals of the herd. Those cows included in the study that were removed from the herd due to health or management reasons were not replaced in the trial; the farm manager and workers were at no point informed about the results of the laboratory tests for MAP during the study.

\section{Sampling and Sample Processing}

Milk, fecal, and blood samples were obtained at each sampling, except for bulk tank milk samples that were not taken in the first and second herd investigation (Table 1).

For individual milk sampling, a 50-mL pooled milk sample from all 4 quarters of the udder was collected aseptically before milking from every cow included in the study. Bulk tank milk samples were taken aseptically before and after pasteurization at each sampling, starting in the first follow-up investigation. Fecal samples were collected from the rectum using disposable plastic gloves, and blood samples were obtained by tail vein venipuncture using Vacuette tubes with a Z Serum Clot Activator (Greiner Bio-One GmbH, Kremsmünster, Austria).

One vial of the milk samples was stored cooled until $\mathrm{qPCR}$ was performed, whereas the other vial was stored cooled overnight, followed by centrifugation for 10 min at $450 \times g$ and harvesting of the milk serum, which was thereafter frozen at $-20^{\circ} \mathrm{C}$ until the ELISA was performed. Fecal samples were stored cooled until processing for $\mathrm{qPCR}$ and blood samples were centrifuged for $5 \mathrm{~min}$ at $850 \times \mathrm{g}$, the serum was harvested, and then stored at $-20^{\circ} \mathrm{C}$ until further investigation.

\section{Testing of the Samples}

Milk samples were examined for MAP by qPCR starting at the second herd investigation as well as by a commercial ELISA at the 3 herd investigations. Fecal samples were tested for MAP by bacteriological culture at the first herd sampling and by $\mathrm{qPCR}$ at the second herd investigation, follow-up investigations, and the third herd investigation. Blood samples were tested for specific antibodies against MAP by the same commercial ELISA test as used for milk at the herd investigations at the beginning and the end of the study (Table 1).

For the qPCR testing of the milk samples, an Adiapure ParaTB Milk kit (Adiagene, Saint-Brieuc, France) was used. Briefly, $10 \mathrm{~mL}$ of milk were mixed with $1 \mathrm{~mL}$ of lysis buffer, and then magnetic beads were added and put on a magnetic rack for fixation. The supernatant was then discharged and lysis buffer and $300 \mathrm{mg}$ of glass beads were added to the new suspension. Samples were homogenized at $30 \mathrm{~Hz}$ for $10 \mathrm{~min}$, followed by centrifugation for $5 \mathrm{~min}$ at $7,500 \times g$. Twenty microliters of lysis buffer was then added and incubated for 10 min at $70^{\circ} \mathrm{C}$ and $15 \mathrm{~min}$ by $95^{\circ} \mathrm{C}$. Amplification of the IS900 segment of the extracted DNA was performed as previously described (Geisbauer et al., 2007).

Bacterial culture of the fecal samples from the first herd investigation was carried out on Herrold's egg yolk medium with and without mycobactin, as described before (Geisbauer et al., 2007). Fecal samples were incubated for $12 \mathrm{wk}$ at $37^{\circ} \mathrm{C}$ and examined for bacterial growth once per week. All the fecal samples collected after the first herd investigation were tested by realtime qPCR, based on the amplification of the DNA segment IS900, as described by Geisbauer et al. (2007).

Milk and blood samples were tested for specific antibodies against MAP by means of a commercial indirect ELISA test. The test used was the Svanovir ELISA (Svanova Biotech AB, Uppsala, Sweden), performed according to the instructions for milk and blood samples provided by the manufacturer.

\section{Statistical Analysis}

For the description of the long-term performance, the results of the 63 selected animals in the 3 herd investigations together with the 12 follow-up investigations were considered. As MAP was detected only in

Table 1. Outline of the Mycobacterium avium ssp. paratuberculosis (MAP)-testing scheme throughout the study ${ }^{1}$

\begin{tabular}{|c|c|c|c|c|c|c|c|}
\hline \multirow[b]{2}{*}{ Item } & \multirow{2}{*}{$\begin{array}{l}\text { Cows } \\
\text { tested }\end{array}$} & \multicolumn{2}{|c|}{ Individual milk } & \multicolumn{2}{|c|}{ Bulk tank milk } & \multirow{2}{*}{$\begin{array}{l}\text { Feces } \\
\text { MAP }^{2}\end{array}$} & \multirow{2}{*}{$\begin{array}{l}\text { Blood } \\
\text { ELISA }\end{array}$} \\
\hline & & PCR & ELISA & Raw & Pasteurized & & \\
\hline 2. Herd investigation & $>1.5 \mathrm{yr}$ & + & + & - & - & + & + \\
\hline 3. Herd investigation & $>1.5 \mathrm{yr}$ & + & + & + & + & + & + \\
\hline Follow-up investigations & 63 selected & + & - & + & + & + & - \\
\hline
\end{tabular}

${ }^{1}-=$ test not performed; $+=$ test performed .

${ }^{2}$ Bacteriological culture in the first herd investigation and PCR in the remaining investigations. 
Table 2. Milk, fecal, and blood results (in \%) from the herd investigations for Mycobacterium avium ssp. paratuberculosis (MAP) ${ }^{1}$

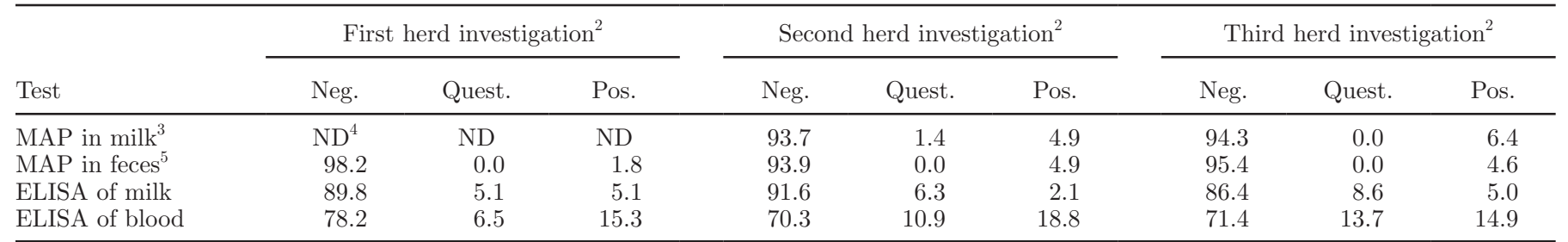

${ }^{1}$ First investigation $=157$ milk samples and $170 \mathrm{blood} /$ feces samples; second investigation $=142$ milk samples and 165 blood $/$ feces samples; third investigation $=140 \mathrm{milk}$ samples and $175 \mathrm{blood} /$ feces samples.

${ }^{2} \mathrm{Neg} .=$ negative test result; Quest. = questionable test result; Pos. = positive test result.

${ }^{3}$ Detection of MAP by PCR.

${ }^{4} \mathrm{ND}=$ not done.

${ }^{5}$ Detection of MAP by PCR or solid culture.

a few samples, the results of fecal culture and realtime qPCR were combined. To assess the association between the results of MAP detection in milk and feces, the extension of the Fisher exact test to general row $x$ column $(\mathrm{R} \times \mathrm{C})$ tables, known as the Freeman-Halton test (Freeman and Halton, 1951), and the $\chi^{2}$ test statistic were applied. Due to the low cell frequencies in most of the analyzed 2-way contingency tables, the Fisher exact test was preferred to the $\chi^{2}$ test in these cases. The Fisher exact test is inherently 2 sided and the alternative hypothesis is defined in terms of general association. A small $P$-value supports the alternative hypothesis of association between the row and column variables, with an assessed level of significance of $\alpha=$ $5 \%$ for all statistical tests. To estimate the magnitude of the agreement between 2 different laboratory tests, a kappa statistical analysis was performed (Cohen, 1960), with a kappa coefficient of -1 indicating complete negative agreement, +1 complete positive agreement, and 0 meaning no agreement between the results.

\section{RESULTS}

\section{Herd Investigations}

Milk samples from 157 cows as well as blood and fecal samples from 170 cows were collected in the first herd investigation, whereas 142 milk samples and 165 blood and fecal samples were obtained in the second herd investigation. In the terminal herd investigation, a total of 140 milk and 175 blood and fecal samples were tested. Of the 170 cows sampled in the first herd investigation, $79(46.5 \%)$ were still in the herd at the terminal herd investigation. Thus, taking the study period of 23 mo into account, an annual culling rate of $27.9 \%$ can be calculated.

The results of the 3 herd investigations are shown in Table 2. Mycobacterium avium ssp. paratuberculosis was detected in $7(4.9 \%)$ of the milk samples at the second and in $9(6.4 \%)$ at the third herd investigation.
Fecal shedding of the bacterium could be detected in 3 $(1.8 \%)$ to $8(4.9 \%)$ of the animals. The ELISA results showed high variation, both in milk and blood. Of the milk samples, $3(2.1 \%)$ to $8(5.1 \%)$ were positive and $26(14.9 \%)$ to $31(18.8 \%)$ of the blood samples were ELISA positive.

\section{Evolution of MAP Shedding into the Milk and Feces of Selected Cows}

During the study period of 23 mo, 24 (38.1\%) of the 63 cows included in the study were culled (Table 3 ). Of these cows, 11 had a MAP-infected status and 13 belonged to the group of MAP-noninfected animals. Therefore, the annual culling rate of the monthly tested 63 cows was calculated to be $19.8 \%$.

The shedding patterns of MAP in the milk and feces of cows shedding the bacterium at any time during the investigation are shown in Table 4 . In the second sampling, 5 cows with a MAP-infected status shed the bacterium into milk. After that, MAP was detected in milk samples from 1 MAP-infected cow at the sixth, seventh and eighth investigation. Cows assigned a MAP-noninfected status did not shed the bacterium into milk except for the fifth (1), sixth (2), and last (3) investigation.

Fecal shedding was detected on 8 of the 15 sampling dates in MAP-infected cows, with a higher number of positive animals at the beginning of the study. Only 1 fecal-positive cow was found in the fourth and sixth investigation in the MAP-noninfected group.

Mycobacterium avium ssp. paratuberculosis shedding into milk was detected in 13 different cows during the study; 7 of these cows had a MAP-infected status, and 6 were assigned a MAP-noninfected status. Only 1 cow was positive twice on 2 adjacent sampling dates and the remaining 12 cows had 1 MAP-positive milk sample only. From the 13 cows shedding MAP into milk, 5 cows also showed fecal shedding during the trial, 3 of them being chronologically related to the positive milk sam- 
Table 3. Number of the 63 selected cows sampled and culled per investigation

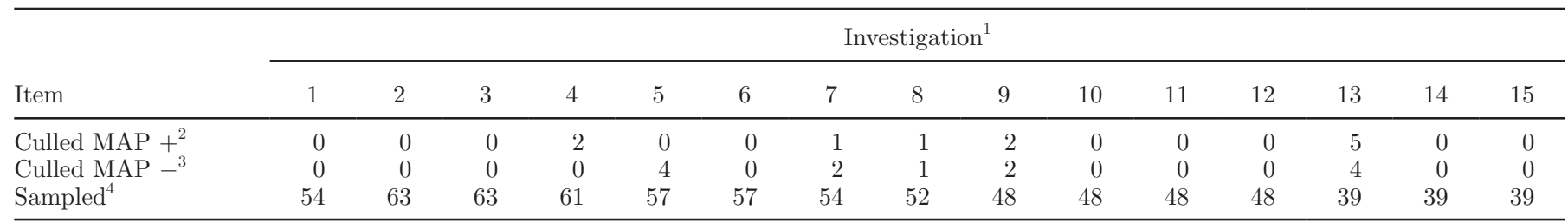

${ }^{1}$ Investigations 1, 2, and 15: cows tested as part of the first, second, and third herd investigation; investigations 3 to 14 : monthly follow-up investigations of selected cows.

${ }^{2}$ Number of Mycobacterium avium ssp. paratuberculosis (MAP)-infected cows culled.

${ }^{3}$ Number of MAP-noninfected cows culled.

${ }^{4}$ Number of cows sampled per investigation.

ples. A significant positive association could be found between MAP shedding into milk and feces in both the Fisher exact and the $\chi^{2}$ test (the kappa value was 0.16 ).

Figure 1 shows that the number of cows with positive MAP milk results was below $5 \%$ most of the time. The highest percentage of positive samples was found in the second sampling $(7.9 \%)$, followed by the last investigation $(7.7 \%)$ and $5.3 \%$ in the sixth sampling.

\section{MAP in Bulk Tank Milk Samples}

The bulk tank milk samples (raw and pasteurized) tested negative for MAP by qPCR throughout the entire study.

\section{DISCUSSION}

The culling rate of the 63 cows under investigation was considerably lower than that of the whole herd, indicating that possible MAP infections were, in an early stage, not causing an increased culling rate. The prevalence of MAP-shedding animals in the study herd can be estimated to be around $5 \%$, based on the MAP detection in milk and feces in the 3 herd investigations. The number of milk and feces MAP-positive cattle was similar, with more cows shedding the bacterium into milk than into feces in the third herd investigation. This is consistent with Gao et al. (2009), who

Table 4. Shedding patterns of Mycobacterium avium ssp. paratuberculosis (MAP) in milk and feces of cows found MAP-positive throughout the trial $(\mathrm{n}=24)$

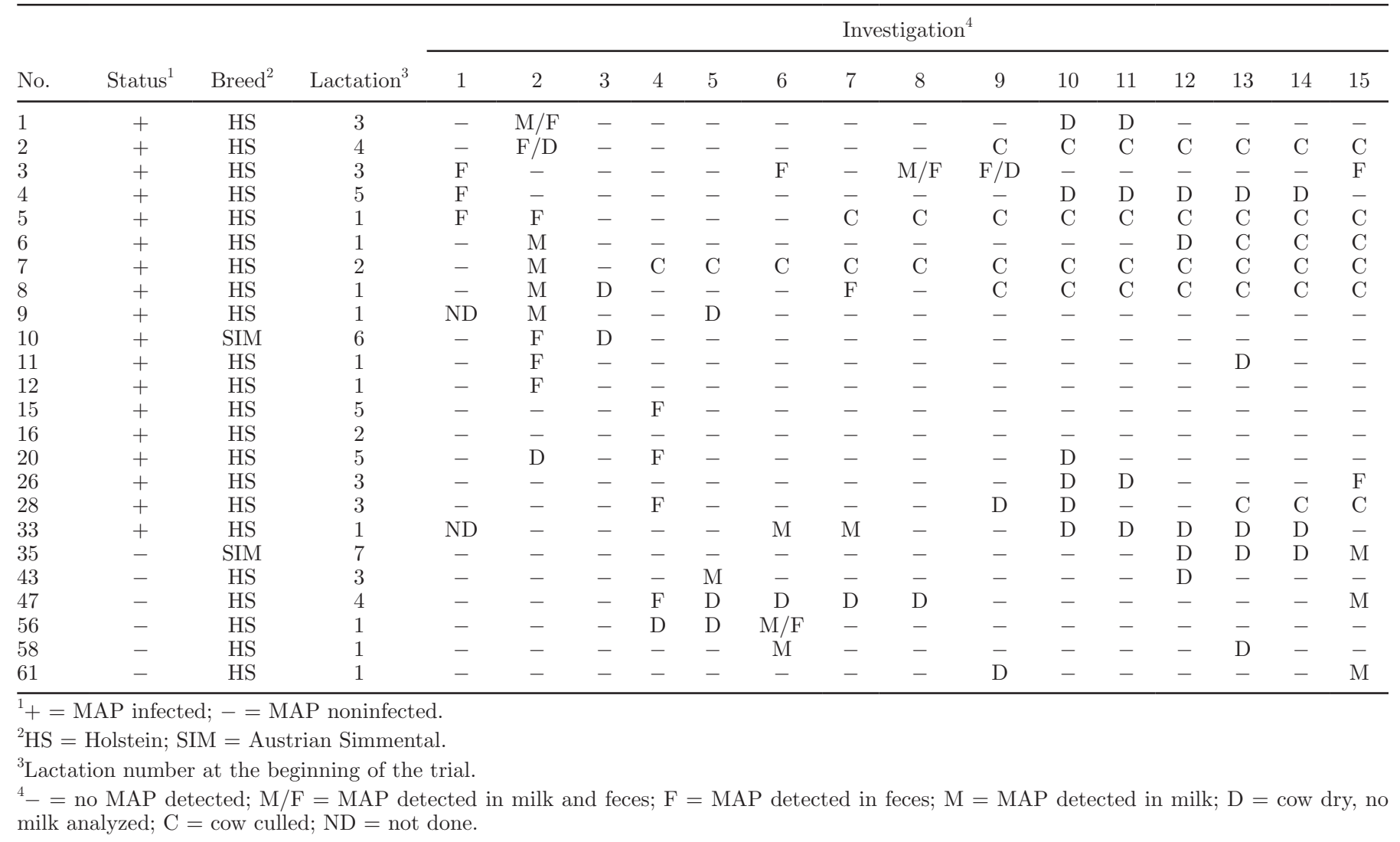




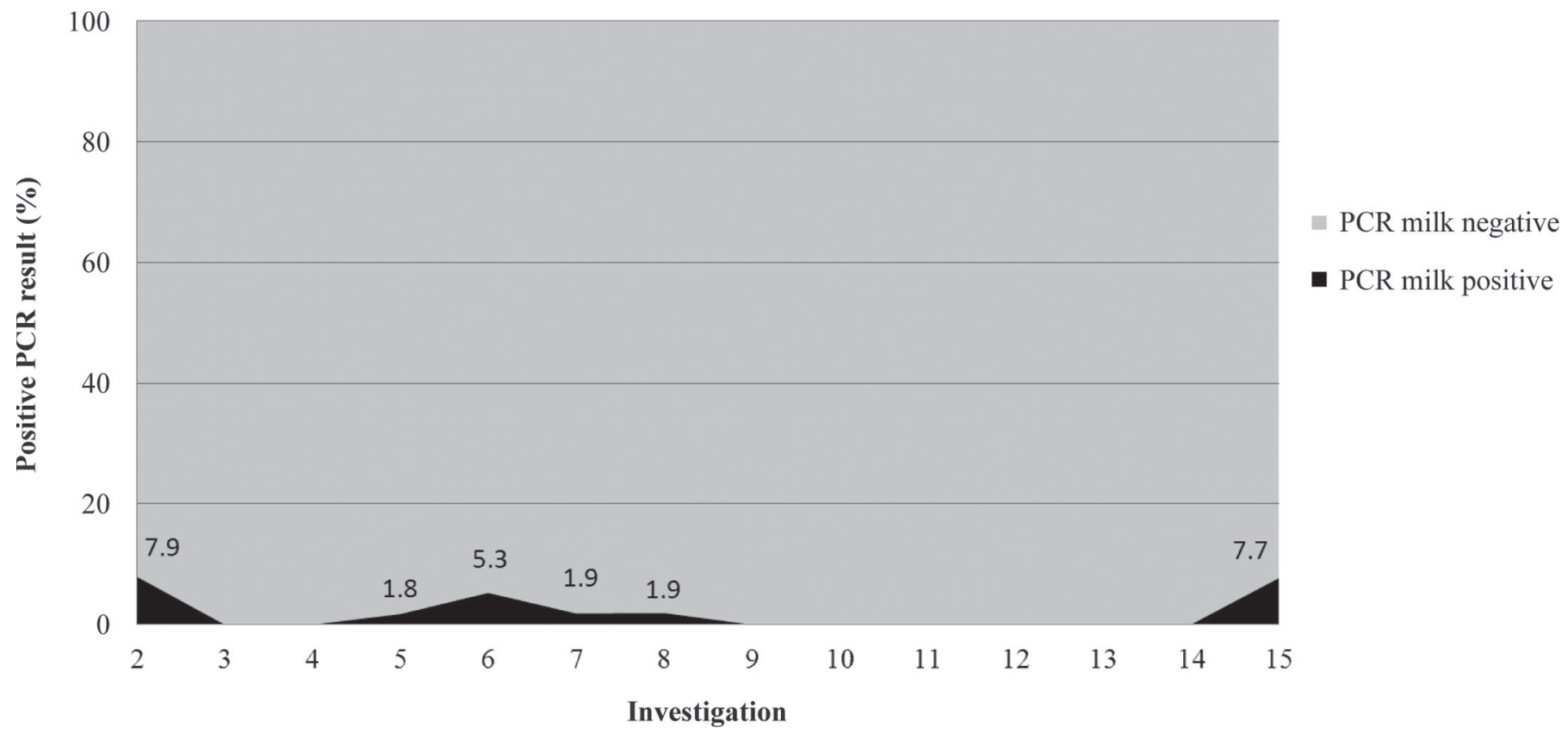

Figure 1. Percentage of cows with positive milk PCR (for DNA segment IS900) results for Mycobacterium avium ssp. paratuberculosis (MAP) during the study period.

also found comparable results between the detection of MAP in feces and milk, but with a (not significant) higher amount of positive fecal samples.

The blood ELISA results from the herd investigations of the present study indicate a higher prevalence of JD than what has been found in direct laboratory tests. Previous studies also reported a larger number of serologically positive animals in herds with JD than those animals actually shedding MAP into feces or milk (Pinedo et al., 2008; Diéguez et al., 2009). Furthermore, it was determined that only $17.3 \%$ of ELISA-positive animals also show positive results in fecal culture (Muskens et al., 2003). Together with the absence of clinical cases of JD during the study period, it can be assumed that the MAP herd prevalence was most accurately assessed by the blood ELISA between 15 and 19\%. Of course, as for all ELISA methods, the possibility of false-positive results leading to an overestimation of the herd prevalence always has to be considered.

Whether or not milk ELISA tests are less sensitive than serum ELISA tests, as seen in this study, is a controversial point and is dependent on the test kit and the study design used (Collins et al., 2005; van Weering et al., 2007; Nielsen and Toft, 2008). The ELISA used in the present study is known to have a sensitivity of up to $40 \%$ but rather low specificity of $91 \%$ in blood samples (Nielsen and Toft, 2008). Milk ELISA results varied between samplings to a certain extent. Differences in ELISA results between multiple samplings have been reported before (Hirst et al., 2002; Buergelt and Wil- liams, 2004). A difference in the performance of ELISA tests according to the MAP infection status of the sampled individuals and population was also highlighted by Nielsen (2008). In accordance with the results of the present study, this confirms that the ELISA results, especially from the milk samples, should not be used for the assessment of the JD status of single cows when applied only once, and should always be interpreted with caution when used as a screening test for JD.

The monthly milk sampling of selected cows revealed low levels of MAP shedding in both the animals of the assigned MAP-infected and noninfected group. It is unknown as to whether the positive milk samples contained the whole bacterium or only DNA fragments of MAP, as no bacterial culture of the milk samples was performed. The low levels of MAP shedding into milk are consistent with the results of Jayarao et al. (2004), who found 2.8\% MAP-positive milk samples in affected dairy herds as well as Bosshard et al. (2006), who reported 3.6\% PCR-positive milk samples in healthy slaughter cattle. Other studies found higher numbers of cows shedding MAP into milk. Buergelt and Williams (2004) reported that 8 to $22 \%$ of cows with subclinical JD shed MAP into milk and Pillai and Jayarao (2002) detected the bacterium in $33 \%$ of cows in a MAPpositive dairy herd. In another study, it was estimated that up to $50 \%$ of ELISA-positive cows also show positive PCR results in milk (Wiszniewska-Łaszczych et al., 2009). The results of the present study indicate that subclinically infected cows only occasionally shed MAP 
into milk and that the shedding of the bacterium into milk can be absent or under the detection limit of PCR over a long period of time.

In the present study, MAP was not detected by qPCR in any raw or pasteurized bulk tank milk sample throughout the study period. Slaná et al. (2009) repeatedly investigated $7 \mathrm{JD}$-positive dairy farms for MAP in bulk tank milk by culture and qPCR and also found no positive sample in 2 of these farms. Three more farms gave only 1 positive result and only 2 farms were positive at more than 1 sampling with one of them showing positive results in bacteriological culture (Slaná et al., 2009). In another study, poor sensitivity and specificity for the detection of MAP in bulk tank milk samples with qPCR of 21 and $50 \%$, respectively, were reported (Jayarao et al., 2004). In contrast to these studies and the results of the present study, Stabel et al. (2002) found $77.4 \%$ MAP-positive bulk tank milk samples by qPCR from dairy herds, with at least 1 cow shedding the bacterium into feces. In herds affected by JD but without fecal-positive animals, $52.4 \%$ of the bulk tank milk samples were found positive for MAP by PCR in the same study (Stabel et al., 2002). The absence of MAP-positive bulk tank milk samples in the present study might have been caused either by the low prevalence of cows shedding MAP into milk or by the failure of the qPCR used. Because the molecular detection was performed in a certified laboratory and positive and negative controls were included at all times, complete failure of the detection method leading to false-negative results through the entire study seems to be very unlikely. The detection limit for PCR in bulk tank milk varies depending on the protocol used (Slana et al., 2008). A detection limit of 1 to $10^{2} \mathrm{cfu}$ of $\mathrm{MAP} / \mathrm{mL}$ was reported for artificially contaminated bulk tank samples and a limit of $0.87 \times 10^{1}$ to $5 \times$ $10^{2} \mathrm{cfu}$ in naturally contaminated samples, respectively (Slana et al., 2008). The dilution of the milk from a few cows shedding MAP into milk with MAP-negative milk from about 130 herd mates within the bulk tank may have caused MAP concentrations below the qPCR detection limit in the bulk tank milk samples. This dilution, together with a further significant reduction in the amount of viable MAP during pasteurization (Slana et al., 2008), decreases the risk of MAP-positive retail milk and milk products.

The fecal results of the present study show that MAP was not frequently shed into feces of cows without clinical JD. Only 2 of the monthly sampled cows shed the bacterium more than 1 time and only 1 cow more than 2 times. This indicates that MAP is shed into the feces of cows with subclinical JD at a low frequency and for a limited period of time only. Therefore, the consequent and early culling of cows with clinical JD helps to reduce the contamination of the environment with MAP, decreases the infection pressure within the herd, and thereby helps to prevent new infections. Culling of animals with clinical JD is directed by the Austrian Paratuberculosis Regulation (Khol et al., 2007). This control measure can be performed in most farms with reasonable effort and poses a powerful tool against JD when combined with hygienic precautions as part of good agricultural practice, as foreseen in the Austrian Paratuberculosis Regulation. The US National Advisory Committee on Microbiological Criteria for Foods (2010) states that milk is a likely source of MAP for humans and concludes that the control of MAP in cattle would also largely eliminate the source of this bacterium in other animals, food, and water.

The positive association between MAP shedding into milk and feces found in the present study is supported by previous reports. Sweeney et al. (1992) and Streeter et al. (1995) found $11.6 \%$ and up to $22.2 \%$ culturepositive milk samples in cows shedding MAP into their feces, with a positive correlation between MAP-positive milk samples and heavy fecal shedding. In the present study, the interpretation of the results of the test agreement has to be done with caution because the kappa values are low and the associations are mostly based on concordant negative results. Due to the positive association of MAP shedding into milk and feces, the culling of animals with advanced JD, as directed by the Austrian Paratuberculosis Regulation (Khol et al., 2007), can contribute to a lower prevalence of MAP shedding into milk and thereby helps to reduce the entry of the bacterium into the food chain.

\section{CONCLUSIONS}

From the results of the present study, it can be concluded that MAP is shed into milk in only a small percentage of cows with subclinical JD for a limited period of time and is positively associated with MAP shedding into feces. Bulk tank milk samples were negative throughout the study, both raw and pasteurized. These findings indicate that dairy herds subclinically infected with JD pose a minor source for human MAP consumption with milk and milk products.

\section{ACKNOWLEDGMENTS}

This study was part of the project "Long-term investigation on JD in an Austrian dairy herd" (GZ:BMGF70420/0131-IV/6/2005) that is supported by the Austrian Federal Ministry of Health (Vienna, Austria).

\section{REFERENCES}

Barkema, H. W., J. W. Hesselink, S. L. B. McKenna, G. Benedictus, and H. Groenendaal. 2010. Global prevalence and economics of 
infection with Mycobacterium avium ssp. paratuberculosis in ruminants. Pages 10-21 in Paratuberculosis: Organism, Disease, Control. 1st ed. M. A. Behr and D. M. Collins, ed. CABI, Wallingford, UK.

Bosshard, C., R. Stephan, and T. Tasara. 2006. Application of an F 57 sequence-based real-time PCR assay for Mycobacterium paratuberculosis detection in bulk tank raw milk and slaughtered healthy dairy cows. J. Food Prot. 69:1662-1667.

Buergelt, C. D., and J. E. Williams. 2004. Nested PCR on blood and milk for the detection of Mycobacterium avium ssp. paratuberculosis DNA in clinical and subclinical bovine paratuberculosis. Aust. Vet. J. 82:497-503.

Cohen, J. 1960. A coefficient of agreement for nominal scales. Educ. Psychol. Meas. 20:37-46.

Collins, M. T. 1996. Diagnosis of paratuberculosis. Vet. Clin. North Am. Food Anim. Pract. 12:357-371.

Collins, M. T., S. J. Wells, K. R. Petrini, J. E. Collins, R. D. Schultz, and R. H. Whitlock. 2005. Evaluation of five antibody detection tests for diagnosis of bovine paratuberculosis. Clin. Diagn. Lab. Immunol. 12:685-692.

Diéguez, F. J., A. M. González, S. Menéndez, M. J. Vilar, M. L. Sanjuán, E. Yus, and I. Arnaiz. 2009. Evaluation of four commercial serum ELISAs for detection of Mycobacterium avium ssp. paratuberculosis infection in dairy cows. Vet. J. 180:231-235.

Fecteau, M. E., and R. H. Whitlock. 2010. Paratuberculosis in cattle Pages 159-170 in Paratuberculosis: Organism, Disease, Control 1st ed. M. A. Behr and D. M. Collins, ed. CABI, Wallingford, UK.

Feller, M., K. Huwiler, R. Stephan, E. Altpeter, A. Shang, H. Furrer, G. E. Pfyffer, T. Jemmi, A. Baumgartner, and M. Egger. 2007. Mycobacterium avium subspecies paratuberculosis and Crohn's disease: A systematic review and meta-analysis. Lancet Infect. Dis. 7:607-613.

Freeman, G. H., and J. H. Halton. 1951. Note on an exact treatment of contingency, goodness of fit and other problems of significance. Biometrika 38:141-149.

Gao, A., J. Odumeru, M. Raymond, S. Hendrick, T. Duffield, and L. Mutharia. 2009. Comparison of milk culture, direct and nested polymerase chain reaction (PCR) with fecal culture based on samples from dairy herds infected with Mycobacterium avium ssp. paratuberculosis. Can. J. Vet. Res. 73:58-64.

Geisbauer, E., J. L. Khol, M. Wassertheurer, J. Damoser, E. Österreicher, M. Dünser, S. Revilla-Fernández, and W. Baumgartner. 2007. Long-term investigation in an Austrian dairy herd with low prevalence of paratuberculosis detection of antibodies in blood and milk. Vet. Q. 29:138-148.

Groenendaal, H., and F. J. Zagmutt. 2008. Scenario analysis of changes in consumption of dairy products caused by a hypothetical causal link between Mycobacterium avium subspecies paratuberculosis and Crohn's disease. J. Dairy Sci. 91:3245-3258.

Hasonova, L., and I. Pavlik. 2006. Economic impact of paratuberculosis in dairy cattle herds: A review. Veterinarni Medicina 51:193-211.

Hirst, H. L., F. B. Garry, and M. D. Salman. 2002. Assessment of test results when using a commercial enzyme-linked immunosorbent assay for diagnosis of paratuberculosis in repeated samples collected from adult dairy cattle. J. Am. Vet. Med. Assoc. 220:1685-1689.

Hruska, K., I. Slana, P. Kralik, and I. Pavlik. 2011. Mycobacterium avium ssp. paratuberculosis in powdered infant milk: F 57 competitive real time PCR. Veterinarni Medicina 56:226-230.

Jayarao, B. M., S. R. Pillai, D. R. Wolfgang, D. R. Griswold, C. A Rossiter, D. Tewari, C. M. Burns, and L. J. Hutchinson. 2004. Evaluation of IS900-PCR assay for detection of Mycobacterium avium subspecies paratuberculosis infection in cattle using quarter milk and bulk tank milk samples. Foodborne Path. Dis. 1:17-26.

Khol, J. L., J. Damoser, M. Dünser, and W. Baumgartner. 2007. Paratuberculosis, a notifiable disease in Austria-Current sta- tus, compulsory measures and first experiences. Prev. Vet. Med. $82: 302-307$

Muskens, J., M. H. Mars, A. R. W. Elbers, K. Van Maanen, and D. Bakker. 2003. The results of using faecal culture as confirmation test of paratuberculosis-seropositive dairy cattle. J. Vet. Med. B Infect. Dis. Vet. Public Health 50:231-234.

National Advisory Committee on Microbiological Criteria for Foods. 2010. Assessment of food as a source of exposure to Mycobacterium avium subspecies paratuberculosis (MAP). J. Food Prot. 73:1357-1397

Nielsen, S. S. 2008. Transitions in diagnostic tests used for detection of Mycobacterium avium ssp. paratuberculosis infections in cattle. Vet. Microbiol. 132:274-282.

Nielsen, S. S., K. K. Nielsen, A. Huda, R. Condron, and M. T. Collins. 2001. Diagnostic techniques for paratuberculosis. Bull. IDF 362:5-17.

Nielsen, S. S., and N. Toft. 2008. Ante mortem diagnosis of paratuberculosis: A review of accuracies of ELISA, interferon- $\gamma$ assay and faecal culture techniques. Vet. Microbiol. 129:217-235.

OIE (Office International des Epizooties). 2010. Manual of diagnostic tests and vaccines for terrestrial animals. Part 2. OIE, Paris, France.

Pillai, S. R., and B. M. Jayarao. 2002. Application of IS900 PCR for detection of Mycobacterium avium ssp. paratuberculosis directly from raw milk. J. Dairy Sci. 85:1052-1057.

Pinedo, P. J., D. O. Rae, J. E. Williams, G. A. Donovan, P. Melendez, and C. D. Buergelt. 2008. Association among results of serum ELISA, fecal culture and nested PCR on milk, blood and faeces for the detection of paratuberculosis in dairy cows. Transbound Emerg. Dis. 55:125-133.

Slaná, I., M. Bartoš, P. Roubal, V. Babák, and I. Pavlík. 2009. Mycobacterium avium ssp. paratuberculosis and $M$. a. avium detected by culture, IS 900 and IS 901 highly sensitive PCR in bulk tank milk from dairy herds in the Czech Republic between 2002 and 2004 Czech J. Food Sci. 27:372-378.

Slana, I., F. Paolicchi, B. Janstova, P. Navratilova, and I. Pavlik. 2008 Detection methods for Mycobacterium avium ssp. paratuberculosis in milk and milk products: A review. Veterinarni Medicina $53: 283-306$

Stabel, J. R., S. J. Wells, and B. A. Wagner. 2002. Relationships between fecal culture, ELISA, and bulk tank milk test results for Johne's disease in US dairy herds. J. Dairy Sci. 85:525-531.

Streeter, R. N., G. F. Hoffsis, S. Bech-Nielsen, W. P. Shulaw, and D. M. Rings. 1995. Isolation of Mycobacterium paratuberculosis from colostrum and milk of subclinically infected cows. Am. J. Vet. Res. 56:1322-1324.

Sweeney, R. W., R. H. Whitlock, and A. E. Rosenberger. 1992. Mycobacterium paratuberculosis cultured from milk and supramammary lymph nodes of infected asymptomatic cows. J. Clin. Microbiol. $30: 166-171$

Uzoigwe, J. C., M. L. Khaitsa, and P. S. Gibbs. 2007. Epidemiological evidence for Mycobacterium avium subspecies paratuberculosis as a cause of Crohn's disease. Epidemiol. Infect. 135:1057-1068.

van Weering, H. G. van Schaik, A. van de Meulen, M. Waal, P. Franken, and K. van Maanen. 2007. Diagnostic performance of the Pourquier ELISA for detection of antibodies against Mycobacterium avium subspecies paratuberculosis in individual milk and bulk tank milk samples of dairy herds. Vet. Microbiol. 125:49-58.

Wiszniewska-Łaszczych, A., J. Szteyn, and A. Smolińska. 2009. Analysis of correlations between the occurrence of anti-MAP antibodies in blood serum and the presence of DNA-MAP in milk. Pol. J. Vet. Sci. 12:379-383. 